\title{
SIMULASI PH AIR UNTUK AIR BOILER DAN AIR CHILLER PADA MESIN PRODUKSI REFRIGERATOR DENGAN MENGGUNAKAN LOGIKA FUZZY
}

\author{
Andhika Irawan ${ }^{1}$, Sri Heranurweni ${ }^{2}$, Titik Nurhayati $^{3)}$ \\ ${ }^{1,2,3)}$ Program Studi Teknik ElektroUniversitas Semarang \\ e-mail: andikir@gmail.com ${ }^{1)}$, heranur@usm.ac.id ${ }^{2)}$, titiknur@usm.ac.id ${ }^{3)}$
}

\begin{abstract}
The need for water is very important for the production process, the water quality must also be considered the $\mathrm{pH}$ value so that the water is suitable for use in boilers or chillers. Seeing from these needs a simulation was made on matlab R2017a using a fuzzy toolbox that can find out the water quality with fuzzy mamdani method. This fuzzy logic simulation can determine the standard value of boiler water $\mathrm{pH}$ (10.5-11.5) and the standard $\mathrm{pH}$ value of chiller water (6-8) in the production machine. The methods in fuzzy logic used are mamdani and centroid methods as deffuzification with R2017a matlab simulation tool. The fuzzy inference system used is the mamdani method. This study made a simulation of mamdani method that can determine the quality of the PH water produced by using fuzzy logic. Chiller water $\mathrm{pH}$ can be used if iron ion values (0-2 ppm), silica ions (50-150 ppm), Total Dissolved Solid (TDS) (500-1000 ppm), total Hardness (100-200 ppm), M-alkalinity (500-750 ppm) from the standard value, the $\mathrm{pH}$ of the chiller water can be proven to reach a water $\mathrm{pH}$ value of 6-8. Boiler water $\mathrm{pH}$ can be used if iron ion values (0-2 ppm), silica ions (100-150 ppm), Total Dissolved Solid (TDS) (2000-3500 ppm), total Hardness (0-3 ppm), M-alkalinity (700-800 ppm) from the standard value, the $\mathrm{pH}$ of boiler water can be proven to reach a water $\mathrm{pH}$ value of 10.5-11.5.
\end{abstract}

Keywords: fuzzy logic, Mamdani method, pH of boiler water

\begin{abstract}
ABSTRAK
Kebutuhan air yang sangat penting untuk proses mesin produksi, maka kualitas air juga harus diperhatikan nilai PH supaya air tersebut layak digunakan pada boiler ataupun chiller. Melihat dari kebutuhan tersebut dibuatlah simulasi pada matlab R2017a menggunakan toolbox fuzzy yang dapat mengetahui kualitas air dengan metode fuzzy mamdani. Simulasi logika fuzzy ini dapat mengetahui nilai standart $\mathrm{pH}$ air boiler $(10,5-11,5)$ dan nilai standart $\mathrm{pH}$ air chiller (6-8) pada mesin produksi. Metode pada logika fuzzy yang digunakan adalah metode mamdani dan centroid sebagai deffuzifikasi dengan alat bantu simulasi matlab R2017a. Sistem inferensi fuzzy yang digunakan adalah metode mamdani. Penelitian ini membuat simulasi metode mamdani yang dapat mengetahui kualitas $\mathrm{PH}$ air yang dihasilkan dengan menggunakan logika fuzzy. $\mathrm{pH}$ air Chiller dapat digunakan jika nilai ion besi (0-2 ppm), ion silika (50-150 ppm), Total Dissolved Solid (TDS) (500-1000 ppm), total Hardness (100-200 ppm), M-alkalinity (500-750 ppm) dari nilai standart tersebut $\mathrm{pH}$ air chiller dapat terbukti tercapai nilai $\mathrm{pH}$ air 6-8. $\mathrm{pH}$ air Boiler dapat digunakan jika nilai ion besi (0-2 ppm), ion silika (100-150 ppm), Total Dissolved Solid (TDS) (2000-3500 ppm), total Hardness (0-3 ppm), M-alkalinity (700-800 ppm) dari nilai standart tersebut $\mathrm{pH}$ air boiler dapat terbukti tercapai nilai $\mathrm{pH}$ air 10,5-11,5.
\end{abstract}

Kata Kunci: logika fuzzy, metode Mamdani, pH air Boiler

\section{Pendahuluan}

$\mathrm{K}$ ebutuhan air merupakan salah satu hal yang sangat penting untuk proses mesin produksi, maka kualitas air juga harus diperhatikan nilai $\mathrm{pH}$ supaya air tersebut layak digunakan pada boiler ataupun chiller. Pada suatu proses produksi dalam industri, boiler merupakan suatu pembangkit panas yang pentin Biasanya bagian laboratorium dalam menentukan kualitas air harus melalui instansi lain. Dengan teknologi di bidang elektronika dan instrumentasi yang telah berkembang, maka banyak hal yang dapat dilakukan dengan cepat dan tepat untuk memenuhi kebutuhan manusia. Melihat dari kebutuhan tersebut dibuatlah simulasi menggunakan toolbox fuzzy MATLAB yang dapat mengetahui kualitas air dengan metode fuzzy mamdani. Simulasi menggunakan Logika Fuzzy ini agar dapat memudahkan pekerja bagian Laboratorium untuk menentukan kualitas air yang dibutuhkan mesin produksi.

\section{Sistem Pengolahan Air Pengisi Boiler}

Boiler atau ketel (steam) adalah mesin kalor (thermal engineering) yang akan mengubah energi-energi kimia atau energi otomis menjadi kerja (usaha) [1]. Boiler ini berbentuk bejana tertutup yang digunakan untuk menghasilkan steam adalah suatu alat berbentuk bejana tertutup yang digunakan untuk menghasilkan steam. Steam diperoleh dengan memanaskan bejana yang berisi air dengan bahan bakar [2]. Boiler dirancang 
untuk melakukan atau memindahkan kalor dari suatu sumber pembakaran, yang biasanya berupa

pembakaran bahan bakar. Penggunaan boiler dalam industri produksi refrigerator sebagai pemanas mould/jig dan outer jig serta membantu proses pengembangan chemical pada proses injeksi polyurethane. Suhu yang digunakan untuk memanaskan mould/jig dan outer jig adalah $45-50^{\circ} \mathrm{C}$.

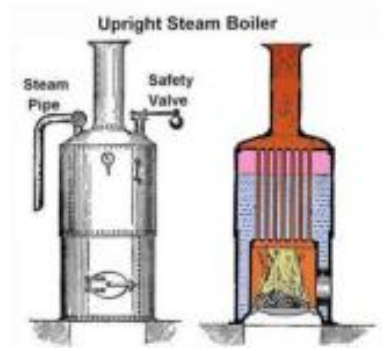

Gambar. 1. Boiler Vertikal [3]

\subsection{Komponen-komponen Boiler}

a. Furnace (Ruang bakar), berfungsi sebagai tempat pembakaran bahan bakar. Bahan bakar dan udara dimasukkan ke dalam ruang bakar sehingga terjadi pembakaran, sehingga dihasilkan sejumlah panas dan nyala api/gas asap. Idealnya, furnace harus memanaskan bahan sebanyak mungkin sampai mencapai suhu yang seragam dengan bahan bakar. Kunci dari operasi furncace agar efisien yaitu terletak pada pembakaran bahan bakar yang sempurna dengan

udara lebih minim. Furnace beroperasi dengan efesiensi yang relatif rendah (paling rendah 7\%) dibandingkan dengan peralatan pembakaran lainnya seperti boiler (dengan efisiensi lebih dari 90\%).

b. Steam Drum, merupakan tempat penampungan air panas dan pembangkitan steam. Steam masih bersifat jenuh (saturated).

c. Superheater, merupakan tempat pengeringan steam dan siap dikirim melalui main steam pipe dan siap untuk menggerakkan turbin steam atau menjalankan proses industri.

d. Turbin Steam, berfungsi untuk mengkonversi energi panas yang dikandung oleh steam menjadi energi putar (energi mekanik). Poros turbin dikopel dengan poros generator sehingga ketika turbin berputar generator juga ikut berputar.

e. Kondensor, berfungsi untuk mengkondensasikan steam dari turbin (steam yang telah digunakan untuk memutar turbin).

f. Generator, berfungsi untuk mengubah energi putar dari turbin menjadi energi listrik.

g. Economizer, merupakan ruangan pemanas yang digunakan untuk memanaskan air dari air yang terkondensasi oleh sistem sebelumnya maupun air umpan baru.

h. Safety valve, merupakan saluran buang steam jika terjadi keadaan dimana tekanan steam melebihi kemampuan boiler menahan tekanan steam. i. Blowdown valve, merupakan saluran yang berfungsi membuang endapan yang berada di dalam pipa steam[3].

\subsection{Sistem Pengolahan Air Pengisi Boiler}

Ada perbedaan ketika mengolah air untuk dijadikan sebagai air minum dibandingkan dengan untuk umpan boiler. Proses pengolahan air minum mineral-mineral yang ada dalam air tidak akan dihilangkan, tetapi hal ini tidak boleh terjadi dalam pengolahan air untuk umpan boiler, juga pada air umpan boiler tidak perlu diberi desinfektan. Jika air yang digunakan sebagai pengisi boiler tanpa pengolahan terlebih dahulu, maka garam - garam kalsium dan magnesium terkandung dalam air akan mengendap karena terkena panas. Endapan ini melekat pada dinding - dinding boiler menjadi kerak. Ada dua jenis pengolahan air pengisi boiler, yaitu pengolahan eksternal dan pengolahan internal.

a. Pengolahan Eksternal, yaitu proses menghilangkan kesadahan dan partikel-partikel asing dalam air. Pengolahan ini berupa pemberian obat-obatan atau pengolahan yang bersifat mekanis yang dilakukan terhadap air sebelum air masuk kedalam boiler dan pengolahan ini dilakukan diluar boiler.

b. Pengoahan Internal (Internal Treatment) adalah pengkondisian air boiler dengan bahan kimia treatment dan pengaturan lainnya dengan tujuan agar korosi, pengerakan dapat dihindari dan kemurnian uap terjaga baik. Pengolahan ini adalah cara pemberian bahan kimia langsung kedalam boiler bersama-sama dengan air pengisi boiler.

Tabel 1. Syarat Air Pendingin (water cooling)

\begin{tabular}{|l|c|c|}
\hline \multicolumn{1}{|c|}{ KANDUNGAN AIR } & TAILAI STANDART & SATUAN \\
\hline PH & 6 sampai 8 & PH Unit \\
\hline ION BESI & 0 sampai 2 & Ppm \\
\hline ION SILIKA & 50 sampai 150 & Ppm \\
\hline TDS & 500 sampai 1000 & Ppm \\
\hline M-ALKALINITY & 500 sampai 750 & Ppm \\
\hline TOTAL HARDNESS & 100 sampai 200 & Ppm \\
\hline
\end{tabular}

Tabel 2. Syarat Air Boiler

\begin{tabular}{|l|c|c|}
\hline \multicolumn{1}{|c|}{ KANDUNGAN AIR } & NILAI STANDART & SATUAN \\
\hline PH & 10,5 sampai 11,5 & PH Unit \\
\hline ION BESI & 0 sampai 2 & Ppm \\
\hline ION SILIKA & 100 sampai 150 & Ppm \\
\hline TDS & 2000 sampai 3500 & Ppm \\
\hline M-ALKALINITY & 700 sampai 800 & Ppm \\
\hline TOTAL HARDNESS & 0 sampai 3 & Ppm \\
\hline
\end{tabular}

2.3. Parameter Analisis Air Pada Air Umpan Boiler Parameter yang digunakan untuk menganalisa air umpan boiler adalah : a. $\mathrm{pH}$, karena harga $\mathrm{pH}$ pada air 
umpan boiler dan air pendingin penting untuk diperhatikan sebagai mencegah terjadinya korosi. b. Konduktivitas, dimana harga daya hantar listrik dari umpan air boiler deperhatikan untuk mencegah terjadinya endapan kerak pada bagian permukaan perpindahan panas dan juga untuk menjaga kemurnian steam yang terbentuk. c. Kesadahan air, adalah kandungan mineral-mineral tertentu di dalam air, umumnya ion kalsium (Ca) dan magnesium (Mg) dalam bentuk garam karbonat, d. Turbidity, kekeruhan dapat didefinisikan sebagai sifat optic dari suatu larutan yang menyebabkan cahaya melaluinya terabsorbsi atau terbiaskan. Nilai kekeruhan bisa menunjukan tingkat atau kadar padatan tersuspensi didalam air, e. TSS (Total Suspenden Solid), padatan tersuspensi dalam jumlah besar pada air umpan boiler tidak dikehendaki karena dapat menyebabkan terjadinya endapan didalam boiler dan membentuk kerak[4].

\section{SIMULASI KUALITAS PH AIR BOILER}

Ada 5 input variabel untuk mengetahui kualitas $\mathrm{pH}$ air dan 1 output untuk menentukan kualitas $\mathrm{pH}$ air, yang digunakan input di simulasi logika fuzzy. Semua variabel itu akan diproses fuzzifikasi., setelah proses fuzzifikasi, selanjutnya adalah proses implikasi min (penalaran/rules) dengan IF-THEN sesuai himpunan fuzzy. Kata "jika" disebut sebagai anteseden sedangkan kata "maka" disebut sebagai konsekuen. Proses selanjutnya adalah proses defuzzifikasi pengubahan besaran fuzzy yang disajikan dalam bentuk himpunan-himpunan fuzzy keluaran dengan fungsi keanggotaannya yang akan dibutuhkan untuk mengolah data pada sistem yang telah dirancang. Output yang dihasilkan adalah $\mathrm{pH}$ air, yang mana ada 1 output yaitu air boiler dengan $\mathrm{pH}$ air 10,5-11,5 dan air chiller dengan $\mathrm{pH}$ air 6-8.

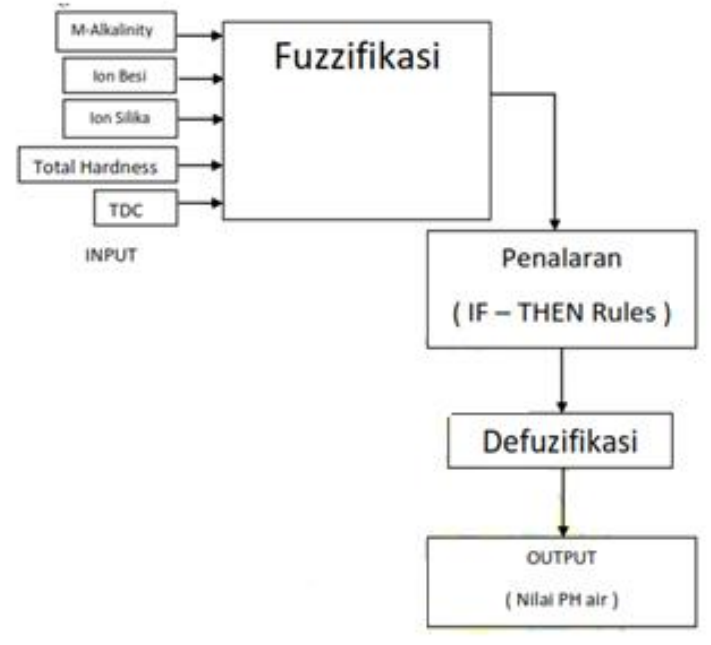

Gambar 2. Diagram Blok Simulasi Kualitas pH Air

Proses yang dilakukan untuk system ini adalah :

- Langkah 1 : Menentukan variabel yang terkait dalam proses yang akan ditentukan dan fungsi fuzzifikasi yang sesuai. Ada 5 variabel yang akan dimodelkan, yaitu: Ion besi, Ion silica, M-alkalinity, total hardness, dan Total Dissolved Solid (TDS).

- Langkah 2 : menentukan nilai input sesuai dengan standart nilai dalam kandungan air

- Langkah 3 : kemudian lanjut ke proses fungsi implikasi yaitu aturan yang digunakan adalah aturan MIN pada fungsi implikasinya.

- Langkah 4 : kemudian lanjut ke proses defuzzifikasi atau penegasan yaitu proses defuzzifikasi yang telah dilakukan maka akan dihasilkan keluaran berupa kualitas $\mathrm{pH}$ air yang dibutuhkan.

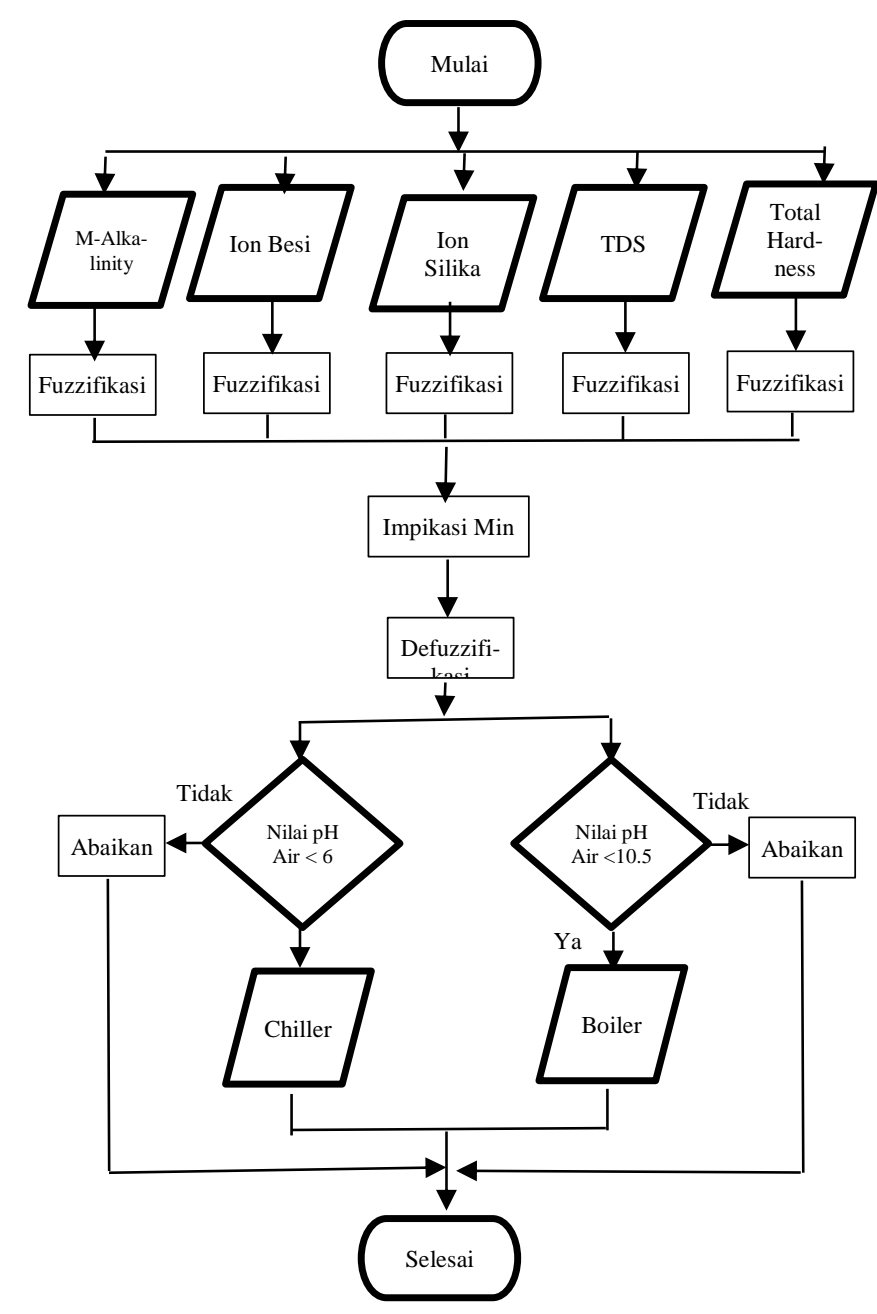

Gambar 4. Diagram Alir Sistem

\section{KUALITAS PH AIR BOILER}

Data-data input yang digunakan sebagai faktor utama yaitu variabel ion silika, ion besi, Total Dissolved Solid (TDS), M-alkalinity, dan total hardness. sedangkan untuk output terdapat 1 variabel, yaitu: ph air. Variabel ion silika memiliki 3 nilai linguistik, yaitu rendah, sedang, dan tinggi ; variable ion besi memiliki 3 nilai linguistik, yaitu rendah, sedang, dan tinggi ; variabel Total Dissolved Solid (TDS) memiliki 3 nilai linguistik, yaitu rendah, sedang, dan tinggi; variabel M- 
alkalinity memiliki 3 nilai linguistik, yaitu rendah, sedang, dan tinggi; variabel total hardness memiliki 3 nilai linguistik, yaitu rendah, sedang, dan tinggi; sedangkan variabel output yaitu $\mathrm{pH}$ air memiliki 2 nilai linguistik yaitu air chiller dan air boiler.

Perhitungan defuzzifikasi dengan cara manual dan program MATLAB memiliki selisih angka sebesar 0.01 sampai 0.03. Jika nilai standart kandungan air sesuai dengan syarat $\mathrm{pH}$ air maka $\mathrm{pH}$ air yang dibutuhkan akan sesuai ( $\mathrm{pH}$ air chiller (6-8) atau $\mathrm{pH}$ air boiler $(10,511,5)$ ). Dan jika nilai standart kandungan air tidak sesuai dengan syarat $\mathrm{pH}$ air maka $\mathrm{pH}$ air akan diabaikan. 3 . Jika nilai kandungan air melebihi standart maka akan menimbulkan efek pada instalasi air chiller maupun air boiler, efek tersebut seperti mudah berkarat (korosif), timbulnya zat kapur, dan kurang baiknya kualitas air. 4 . Terbukti dengan menggunakan logika fuzzy metode mamdani dapat menentukan kualitas pH air chiller (68) dan $\mathrm{pH}$ air boiler $(10,5-11,5)$, adapun himpunan variabel-nya seperti berikut:

- Jika ion silika RENDAH dan ion besi RENDAH dan TDS RENDAH dan M-alkalinity SEDANG dan Total Hardness RENDAH maka terbukti nilai $\mathrm{pH}$ 7,59 dengan kategori air chiller.

- Jika ion silika TINGGI dan ion besi TINGGI dan TDS TINGGI dan M-alkalinity TINGGI dan Total Hardness RENDAH maka terbukti nilai $\mathrm{pH}$ 11,29 dengan kategori air boiler.

\section{KESIMPULAN}

Kesimpulan yang dapat diambila dari penelitian ini adalah :

1. Perhitungan defuzzifikasi dengan cara manual dan program (matlab) memiliki selisih angka sebesar 0.01 sampai 0.03 .

2. Jika nilai standart kandungan air sesuai dengan syarat $\mathrm{pH}$ air maka $\mathrm{pH}$ air yang dibutuhkan akan sesuai $(\mathrm{pH}$ air chiller (6-8) atau $\mathrm{pH}$ air boiler (10,5 11,5) ). Dan jika nilai standart kandungan air tidak sesuai dengan syarat $\mathrm{pH}$ air maka $\mathrm{pH}$ air akan diabaikan.

3. Jika nilai kandungan air melebihi standart maka akan menimbulkan efek pada instalasi air chiller maupun air boiler, efek tersebut seperti mudah berkarat (korosif), timbulnya zat kapur, dan kurang baiknya kualitas air.

4. Terbukti dengan menggunakan logika fuzzy metode mamdani dapat menentukan kualitas $\mathrm{pH}$ air chiller (6-8) dan $\mathrm{pH}$ air boiler (10,5-11,5), adapun himpunan variabel-nya seperti berikut:

- Jika ion silika RENDAH dan ion besi RENDAH dan TDS RENDAH dan M-alkalinity SEDANG dan Total Hardness RENDAH maka terbukti nilai $\mathrm{pH}$ 7,59 dengan kategori air chiller.

- Jika ion silika TINGGI dan ion besi TINGGI dan TDS TINGGI dan M-alkalinity TINGGI dan Total Hardness RENDAH maka terbukti nilai $\mathrm{pH}$ 11,29 dengan kategori air boiler.

\section{DAFTAR PUSTAKA}

[1] Muin, Syamsir A. 1988. Pesawat-pesawat konversi energi I: (ketel uap). Rajawali Press. Jakarta.

[2]Yohana, Eflita dan Askhabulyamin. 2012. Perhitungan efisiensi dan konversi dari bahan bakar solar ke gas pada boiler Ebara HKL 1800 KA. Universitas Diponegoro. Semarang.

[3] Lestari, Puji Astuti. 2011. Termodinamika Teknik I. Politeknik Negeri Sriwijaya. Sriwijaya.

[4] Morgan, Michael. J. 2006. Fundamental of Engineering Thermodynamics. John Wiley and Sons. Inc. 